\title{
Income diversity and neighborhood variation in low birth weight rates, Chicago, 1990-2006: Results using longitudinal and cross-sectional measures
}

\author{
Jessica Kubo ${ }^{1}$, Diana S. Grigsby-Toussaint ${ }^{2^{*}}$ \\ ${ }^{1}$ Department of Statistics, University of Illinois, Urbana Champaign, USA \\ ${ }^{2}$ Department of Kinesiology and Community Health and Division of Nutritional Sciences, University of Illinois, Urbana Champaign, \\ USA; *Corresponding Author: dgrigs1@illinois.edu
}

Received 27 July 2013; revised 2 September 2013; accepted 19 September 2013

Copyright (C) 2013 Jessica Kubo, Diana S. Grigsby-Toussaint. This is an open access article distributed under the Creative Commons Attribution License, which permits unrestricted use, distribution, and reproduction in any medium, provided the original work is properly cited.

\section{ABSTRACT}

Although increased risk for adverse birth outcomes has been associated with neighborhood socioeconomic disadvantage, most studies have used cross-sectional measures to account for neighborhood context. Consequently, dynamic neighborhood processes that may influence adverse birth outcomes are not fully understood. In this study, a longitudinal measure of socioeconomic change was used to explore variation in low birth weight (LBW) rates between 1990 and 2006 in Chicago neighborhoods. A crosssectional measure of neighborhood socioeconomic characteristics was then used to compare the LBW rates across Chicago neighborhoods during the same time frame to determine whether the cross-sectional measure would capture the same nuances in LBW variation as the longitudinal measure. Consistent with previous studies, both measures identified higher low birth weight rates in neighborhoods entrenched in poverty during the study period. However, the longitudinal measure showed that mothers residing in low income neighborhoods with high concentrations of immigrants had LBW rates that were lower than mothers residing in high income neighborhoods. Our results suggest that while cross-sectional measures of neighborhood socioeconomic context may capture global variations in low birth weight rates, longitudinal measures may illuminate subtleties between neighborhoods that might provide an opportunity for targeted policies to reduce adverse maternal and child health outcomes.
Keywords: Low Birth Weight; Neighborhood; Socioeconomic Status

\section{INTRODUCTION}

In the United States (US), low birth weight (LBW), defined as the percentage of babies weighing $<2500$ grams $(5.5 \mathrm{lbs})$ at birth, persists as a major public health problem [1,2]. Between 1970 and 2008, LBW prevalence in the US increased from $7.93 \%$ to $8.18 \%[1,2]$. During this time frame, racial disparities in LBW also persisted, with African-American LBW rates consistently almost twice that of Whites [1]. Several studies have demonstrated that socioeconomic characteristics of neighborhoods may mediate these observed disparities [3-9]. In addition, higher levels of neighborhood deprivation, usually measured using constructs of education, income, poverty, or unemployment, have been found to be predictive of LBW and other adverse birth outcomes [3-7, 9-11].

Notwithstanding the fact that these studies do capture variations in birth outcomes, a major limitation is the use of single decennial census estimates to measure neighborhood context. Although several studies demonstrate that longitudinal measures of neighborhood context may better explain variations in health $[12,13]$, most studies examining neighborhood influences on LBW and other adverse birth outcomes use cross-sectional measures [5, 6,14-17]. In a study by Do [12], results suggest that longitudinal measures of neighborhood context are particularly salient for disentangling health disparities between Blacks and Whites. As such, using cross-sectional measures to investigate differences in birth outcomes between Blacks and Whites in neighborhoods in the US may underestimate or misestimate the gap in LBW rates, par- 
ticularly given dynamic neighborhood processes that might change over time. Neighborhood disinvestment, for example, may impact social networks or access to health service agencies that conceivably influence maternal stress, and as a consequence, increase poor birth outcomes. Conversely, neighborhood revitalization may improve access to better quality foods, and a higher tax base for resources that could result in a more supportive environment for health-promoting behaviors for expectant mothers, thus, reducing LBW risk. In the context of public health planning and surveillance, these neighborhood processes are critical for targeting and tracking interventions, particularly in major metropolitan areas of the US that have experienced substantial changes in socioeconomic composition over the last three decades $[18,19]$. Thus, incorporation of a longitudinal assessment metric of neighborhood processes could provide a more complete picture in understanding LBW risk.

In this study, we use a longitudinal measure of neighborhood socioeconomic change in the city of Chicago to examine associations with trends in LBW rates. Time trends in LBW are examined as well as mean LBW over the study period 1990-2006. We compare the longitudinal measure of neighborhood characteristics to a crosssectional measure of neighborhood characteristics based on quintiles of income categories from the US 2000 census.

\section{METHODS}

\subsection{Low Birth Weight}

Publically available de-identified vital statistics data from the Illinois Project for Local Assessment of Needs (IPLAN) website was used for this study. The IPLAN website serves as a repository for 102 health indicators used to assist health departments with community assessments and five-year planning goals [20]. The Center for Health Statistics at the Illinois Department of Public Health maintains the IPLAN website, updating vital statistics data based on birth certificate records reported by local health departments across the state. Total counts of live births and LBW infants born to Black and White women in each of Chicago's 77 community areas (i.e., neighborhoods) between 1990 and 2005 were abstracted from the IPLAN database. IPLAN defines low birth weight using the conventional definition of weight at birth of less than 2500 grams [21]. The final sample size consisted of 804,289 births; 350,681 to Black mothers, and 453,428 to White mothers.

\subsection{Neighborhood Socioeconomic Context}

\subsubsection{Definition of Neighborhoods}

The administrative unit used for public health planning in the city of Chicago is the community area, which is used as a proxy for neighborhoods in this study [22]. Designated in the 1920's by the Social Science Research Council at the University of Chicago, these 77 areas were intended to reflect the cultural and social history of Chicago [23]. On average, community areas in Chicago consist of 3 to 4 census tracts and the population count may range from approximately 3000 to 120,000 . On average, each community area has 37,000 residents [22].

\subsubsection{Measure of Socioeconomic Change}

An income diversity index of neighborhood socioeconomic context developed by the Metro Chicago Information Center (MCIC), an official census center, was used to characterize neighborhoods. To develop the income diversity index, the MCIC used data available from the Neighborhood Change Database (NCDB), a commercially available database of social, demographic, economic and housing data on census tracts in the US for 1970, 1980, 1990, and 2000 [24]. The purpose for developing the index was to examine trends in the socioeconomic composition of neighborhoods over time in order to develop sound community development policies [25].

Neighborhoods were categorized as stable diversity, emerging low income, emerging high income, desertification, and emerging bipolarity based on patterns of economic change in Chicago community areas over 30 years [25]. Briefly, stable diversity neighborhoods ( $\mathrm{n}=$ 19) consist of community areas that have maintained a socioeconomically diverse population between 1970 and 2000. Emerging low income neighborhoods $(\mathrm{n}=11)$ have experienced a loss of high income families, while the reverse occurred with emerging high income neighborhoods $(n=21)$, where the number of low income families is decreasing. Desertification neighborhoods $(n=11)$ show patterns of entrenched levels of poverty with a predominantly African-American population. Finally, emerging bipolarity neighborhoods $(\mathrm{n}=15)$ show an increase in both high and low income residents. Table 1 summarizes the characteristics of each type of neighborhood based on the index using US Census 2000 data. (For detailed methodology on the MCIC income diversity index, see http://www.mcic.org).

\subsubsection{Quintiles of Low Income Families}

The percent of families considered to be low income in 2000 was obtained from the MCIC database for each of the 77 Chicago neighborhoods. These percentages were used to divide the 77 neighborhoods into quintiles. The first quintile, which contains the lowest percentage of low income families, has 17 neighborhoods. The second has 16 , the third 15 , the fourth 14 , and the fifth 15 . 


\subsubsection{Neighborhood Demographics}

Census 2000 data was obtained for the 77 Chicago neighborhoods from the Chicago Metropolitan Agency for Planning (http://www.cmap.illinois.gov/). Race/ethnicity, percent college educated, percent foreign born, median income, percent in poverty, median property value, percent female-headed households, and percent unemployment were calculated using neighborhood-level data and aggregated by each set of indices used - the IDI and low income quintiles.

\subsection{Statistical Analyses}

Race-stratified mean LBW rates were calculated using counts of LBW and total live births for each neighborhood type based on the income diversity index and for each quintile of low income families in 2000. Simple linear regression was performed for each income diversity index category and each quintile of low income. The year (1990-2006) was used as the predictor, with percent of LBW as the response. $\mathrm{R}^{2}$ values from simple linear regression, as well as estimates and p-values of the intercept and predictors are reported. All analyses were performed using SAS 9.1 (SAS Institute Inc., Cary, NC).

\section{RESULTS}

Demographics from the 2000 census were compared for neighborhoods aggregated using both index methods (IDI and low-income quintiles) in Table 1. It is observed that the range of median incomes in thousands of dollars is lower (28.7 versus 34.4 ) when using the IDI than when using income quintiles. Desertification neighborhoods are $96.2 \%$ Black (quintiles range from 12.2 in $0-20^{\text {th }}$ quintile to 80.7 in $80-100^{\text {th }}$ quintile). Also, while the 60 - $80^{\text {th }}$ quintile is $61.7 \%$ Black, emerging low income neighborhoods are $37.9 \%$ Black.

Between 1990 and 2006, mean LBW rates for Whites ranged from $6.38 \%(95 \% \mathrm{CI}, 6.05,6.71)$ in emerging low income neighborhoods to $7.82 \%$ (95\% CI, 7.07, 8.57) in desertification neighborhoods (Table 2). Linear regression (Table 3) indicates significant increases in LBW rates in emerging low income, emerging bipolarity, stable diversity, and emerging high income neighborhoods during the study period. LBW ranged from $6.61 \%$ $(95 \% \mathrm{CI}, 6.18,7.04)$ in the $0-20$ quintile to $6.83 \%(95 \%$ $\mathrm{CI}, 6.47,7.20)$ in the $80-100$ quintile during the study period. Linear regression results show a significant increase in LBW for all quintiles at the $95 \%$ level of significance.

The mean LBW rates for Black mothers ranged from $13.9 \%(95 \% \mathrm{CI}, 13.5,14.3)$ in emerging low income neighborhoods to $16.3 \%(95 \% \mathrm{CI}, 15.9,16.7)$ in desertification neighborhoods (Table 2). Overall, LBW rates for this demographic showed a downward trend between

Table 1. Selected demographic characteristics of neighborhood socioeconomic context using the US Decennial Census 2000 estimates.

\begin{tabular}{|c|c|c|c|c|c|c|c|c|}
\hline $\begin{array}{l}\text { Income } \\
\text { Diversity } \\
\text { Index } \\
\end{array}$ & $\begin{array}{l}\% \text { foreign } \\
\text { born }\end{array}$ & $\begin{array}{c}\% \text { of adults } \\
\text { with a college } \\
\text { education }\end{array}$ & $\begin{array}{c}\% \text { White } \\
\text { non-Hispanic }\end{array}$ & $\begin{array}{c}\% \text { Black } \\
\text { non-Hispanic }\end{array}$ & $\%$ Hispanic & $\begin{array}{c}\text { Median } \\
\text { property value } \\
\text { in } \$ 1000 \mathrm{~s} \\
\end{array}$ & $\begin{array}{c}\text { Median } \\
\text { household income } \\
\text { in } \$ 1000 \mathrm{~s}\end{array}$ & $\begin{array}{c}\% \text { of families } \\
\text { below poverty } \\
\text { rate }\end{array}$ \\
\hline $\begin{array}{l}\text { Desertification } \\
\qquad N=11\end{array}$ & 1.9 & $13 \%$ & 1.6 & 96.2 & 1.6 & 105.6 & 18.9 & 39.1 \\
\hline $\begin{array}{l}\text { Emerging Low } \\
\text { Income } \\
\mathrm{N}=11\end{array}$ & 28.2 & $16 \%$ & 31.9 & 37.9 & 44.8 & 104.9 & 34.0 & 18.4 \\
\hline $\begin{array}{l}\text { Stable Diversity } \\
\qquad N=19\end{array}$ & 21.8 & $27 \%$ & 33.9 & 45.0 & 20.9 & 147.8 & 40.2 & 13.6 \\
\hline $\begin{array}{l}\text { Emerging High } \\
\text { Income } \\
\mathrm{N}=21\end{array}$ & 19.1 & $39 \%$ & 63.6 & 18.9 & 20.2 & 222.6 & 47.6 & 10.7 \\
\hline $\begin{array}{l}\text { US Census } 2000 \\
\text { Income Quintile }\end{array}$ & $\begin{array}{l}\% \text { foreign } \\
\text { born }\end{array}$ & $\begin{array}{c}\% \text { of adults with } \\
\text { a college } \\
\text { education }\end{array}$ & $\begin{array}{c}\% \text { White } \\
\text { non-Hispanic }\end{array}$ & $\begin{array}{c}\% \text { Black } \\
\text { non-Hispanic }\end{array}$ & $\%$ Hispanic & $\begin{array}{l}\text { Median } \\
\text { property } \\
\text { value } \$\end{array}$ & $\begin{array}{c}\text { Median } \\
\text { household } \\
\text { income }\end{array}$ & $\begin{array}{c}\% \text { of } \\
\text { families below } \\
\text { poverty rate }\end{array}$ \\
\hline $\begin{array}{c}80-100 \\
N=17\end{array}$ & 8.8 & $13 \%$ & 8.4 & 80.7 & 15.5 & 102.0 & 21.4 & 35.0 \\
\hline $\begin{array}{l}60-80 \\
N=16\end{array}$ & 17.0 & $24 \%$ & 19.1 & 61.7 & 18.3 & 129.1 & 31.5 & 21.5 \\
\hline $\begin{array}{l}40-60 \\
N=15\end{array}$ & 27.8 & $23 \%$ & 39.3 & 28.9 & 41.4 & 159.9 & 37.3 & 16.4 \\
\hline $\begin{array}{l}20-40 \\
N=14\end{array}$ & 25.8 & $27 \%$ & 51.9 & 28.8 & 23.0 & 150.8 & 41.3 & 10.5 \\
\hline $\begin{array}{c}0-20 \\
N=15\end{array}$ & 16.7 & $43 \%$ & 75.6 & 12.2 & 11.7 & 238.3 & 55.8 & 4.9 \\
\hline
\end{tabular}


Table 2. Mean low birth weight rate by income diversity index and US Census 2000 quintile of income families for White, Black and combined mothers.

\begin{tabular}{|c|c|c|c|}
\hline & White & Black & Combined \\
\hline All Neighborhoods & $6.78(6.48,7.08)$ & $15.27(14.93,15.61)$ & $10.44(10.12,10.76)$ \\
\hline Income Diversity Index & Mean $(95 \% \mathrm{CI})$ & Mean $(95 \% \mathrm{CI})$ & Mean $(95 \% \mathrm{CI})$ \\
\hline Desertification & $7.82(7.07,8.57)$ & $16.30(15.87,16.73)$ & $15.75(15.41,16.10)$ \\
\hline Emerging Low Income & $6.38(6.05,6.71)$ & $13.89(13.51,14.27)$ & $8.11(7.84,8.39)$ \\
\hline Emerging Bipolarity & $7.15(6.76,7.55)$ & $15.27(14.93,15.61)$ & $10.86(10.56,11.16)$ \\
\hline Stable Diversity & $6.66(6.34,6.99)$ & $14.55(14.17,14.93)$ & $10.41(10.04,10.77)$ \\
\hline \multirow[t]{2}{*}{ Emerging High Income } & $6.85(6.53,7.18)$ & $15.27(14.83,15.72)$ & $8.99(8.71,9.26)$ \\
\hline & White & Black & Combined \\
\hline US Census 2000 Income Quintile & Mean $(95 \% \mathrm{CI})$ & Mean $(95 \% \mathrm{CI})$ & Mean $(95 \% \mathrm{CI})$ \\
\hline $80-100$ & $6.83(6.47,7.20)$ & $15.97(15.56,16.38)$ & $13.26(12.90,13.61)$ \\
\hline $60-80$ & $6.83(6.50,7.17)$ & $14.92(14.55,15.29)$ & $11.43(11.10,11.75)$ \\
\hline $40-60$ & $6.87(6.57,7.17)$ & $15.08(14.64,15.52)$ & $9.24(8.93,9.55)$ \\
\hline $20-40$ & $6.76(6.43,7.09)$ & $14.60(14.07,15.13)$ & $8.61(8.25,8.96)$ \\
\hline $0-20$ & $6.61(6.18,7.04)$ & $14.37(13.89,14.84)$ & $7.86(7.53,8.20)$ \\
\hline
\end{tabular}

Table 3. Results of linear regression of low birth weight rates on years for White, Black, and combined mothers.

\begin{tabular}{|c|c|c|c|c|c|c|}
\hline \multirow[b]{2}{*}{ All Neighborhoods } & \multicolumn{2}{|c|}{ White } & \multicolumn{2}{|c|}{ Black } & \multicolumn{2}{|c|}{ Combined } \\
\hline & 0.0007 & $<0.0001$ & -0.0006 & 0.0127 & -0.0007 & 0.0004 \\
\hline Income Diversity Index & Coefficient & P-value & Coefficient & P-value & Coefficient & P-value \\
\hline Desertification & 0.0012 & 0.3967 & -0.0012 & 0.0009 & -0.0005 & 0.0362 \\
\hline Emerging Low Income & 0.0007 & 0.0029 & -0.0001 & 0.7692 & 0.0003 & 0.0636 \\
\hline Emerging Bipolarity & 0.0011 & 0.0002 & -0.0002 & 0.5674 & -0.0002 & 0.4448 \\
\hline Stable Diversity & 0.0006 & 0.0032 & -0.0002 & 0.5168 & -0.0007 & 0.0203 \\
\hline \multirow[t]{2}{*}{ Emerging High Income } & 0.0007 & 0.0009 & -0.0004 & 0.3986 & -0.0004 & 0.0302 \\
\hline & White & & Black & & Combined & \\
\hline US Census 2000 Income Quintile & Coefficient & P-value & Coefficient & P-value & Coefficient & P-value \\
\hline $80-100$ & 0.0006 & 0.0474 & -0.0008 & 0.0146 & -0.0007 & 0.0075 \\
\hline $60-80$ & 0.0006 & 0.0102 & -0.0004 & 0.2330 & -0.0003 & 0.1360 \\
\hline $40-60$ & 0.0004 & 0.0254 & 0.0001 & 0.8527 & -0.0002 & 0.2588 \\
\hline $20-40$ & 0.0006 & 0.0035 & -0.0006 & 0.3283 & -0.0004 & 0.1227 \\
\hline $0-20$ & 0.0014 & $<0.0001$ & -0.0007 & 0.1502 & 0.0007 & 0.0014 \\
\hline
\end{tabular}

1990 and $2006(\mathrm{P}<0.05)$, with significant decreases in LBW rates for desertification neighborhoods. Black LBW rates ranged from $14.4 \%(95 \% \mathrm{CI}, 13.9,14.8)$ in the 0 - 20 quintile to $16.0(95 \% \mathrm{CI}, 15.6,16.4)$. A non-significant increase in LBW rates was noted for the 40 - 60 quintile; non-significant decreases occurred in the 0 - 20, $20-40$, and 60 - 80 quintile. Neighborhoods in the 80 - 100 quintile experienced a significant decrease in LBW rates.

Regression results for White mothers were significant for all quintiles, however, for desertification neighborhoods no significant time trend was observed. For Black 
mothers only the 80 - 100 quintile with the highest percentage of low income families had significant regression results; similarly, using the IDI only desertification neighborhoods had significant time trends. Combined results also showed a difference in the two index methods-for Black and White mothers, desertification, stable diversity, and emerging high income had significant time trends; only the $0-20$ and $80-100$ quintiles had significant time trends. Further, the $0-20$ quintile with the least percentage of low income families had a positive slope; emerging high income neighborhoods had a negative slope.

\section{DISCUSSION}

Consistent with other studies exploring adverse birth outcomes and neighborhood context using cross-sectional measures, we found that Black and White women residing in neighborhoods entrenched in poverty, with high concentrations of Blacks, were more likely to have higher LBW risk [3,4]. Additionally, consonant with national estimates, LBW rates for Blacks were consistently double those of Whites for the study period. Notwithstanding, it is interesting to note that emerging low income neighborhoods have the lowest LBW rates of all neighborhoods and seem to confer some protection against LBW risk for both Black and White mothers. This finding may be due to high concentrations of Latino immigrants in these neighborhoods (Table 1), where some studies have suggested that better social support may attenuate the impact of limited material resources on health [26]. Higher LBW risk for Black and White mothers residing in emerging high income neighborhoods may be due to more highly educated women residing in these neighborhoods who tend to be older at first birth [27]. As a consequence of being older at first birth, these women may also be more likely to use assisted reproductive technology that has also been shown to be associated with higher LBW risk [28].

Comparing the two classification schemes, aggregated demographics over 77 neighborhoods using the US census 2000 estimates shows an increasing gradient of percent Black, percent in poverty and proportion of female headed households and a decreasing gradient of median income from the lowest quintile of low income households to the highest. The IDI, on the other hand, shows desertification neighborhoods in stark contrast with other indices for these measures. The IDI as a longitudinal measure appears to better capture the entrenched poverty of the desertification neighborhoods, while the method of income quintiles misses this in the quintile with the highest low income families.

To our knowledge, few studies have undertaken investigations of neighborhood influences on birth outcomes using a longitudinal measure of socioeconomic context.
The income diversity index is particularly unique as it allows us to examine patterns in LBW risk in Chicago neighborhoods while accounting for the influence of neighborhood revitalization and immigration patterns, thus providing a more nuanced view of neighborhood influences on LBW. In addition, the income diversity index was specifically designed to address issues related to community development for the city of Chicago, thus it may serve as a more practical tool for public health planning to address LBW risk.

This study was not without its limitations. First, the use of vital statistics data at the neighborhood level without individual level covariates limited our ability to account for potential confounders. For example, information on mothers' length of residence would have improved our ability to better quantify the influence of neighborhoods on LBW risk. Second, while we had data on racial categories of the mothers in our study, we did not have data on ethnicity. As such, some of the women in our population may be misclassified as Black or White, when their ascribed status was Hispanic. This could account for the lower LBW rates for both Blacks and Whites in the emerging low income neighborhoods in our study. Third, while our measure of neighborhood context accounts for socioeconomic change over a thirtyyear period, it is primarily based on a measure of family income, which is only one aspect of neighborhoods that may influence health.

The goal of this study was to use a longitudinal measure of neighborhood context based on population-based data for LBW in the city of Chicago. While our results corroborate previous findings $[8,10]$ that neighborhoods with high concentrations of African-Americans and high levels of poverty have higher rates of LBW, it also provides a nuanced view of the impact of neighborhood immigrant and revitalization patterns on the birth outcomes of Black and White residents. Thus, measures that seek to capture socioeconomic characteristics of neighborhoods over time may provide better insight for targeted policies to reduce adverse health outcomes as part of city-wide public health planning efforts.

\section{REFERENCES}

[1] Centers for Disease Control and Prevention (2008) Health, United States, 2008 with chart book on trends on the health of Americans. National Center for Health Statistics, Hyattsville.

[2] Martin, J.A., Hamilton, B.E., Ventura, S.J., Osterman, M.J.K, Wilson, E.C. and Mathews, T.J. (2012) Births: Final data for 2010. National Vital Statistics Reports, 61, National Center for Health Statistics, Hyattsville.

[3] Roberts, E.M. (1997) Neighborhood social environments and the distribution of low birthweight in Chicago. American Journal of Public Health, 87, 597-603. 
http://dx.doi.org/10.2105/AJPH.87.4.597

[4] O’Campo P., Burke, J.G., Culhane, J., Elo, I.T., Eyster, J., Holzman, C., Messer, L.C., Kaufman, J.S. and Laraia, B.A. (2008) Neighborhood deprivation and preterm birth among non-Hispanic Black and White women in eight geographic areas in the United States. American Journal of Epidemiology, 167, 155-163.

http://dx.doi.org/10.1093/aje/kwm277

[5] Buka, S.L., Brennan, R.T., Rich-Edwards, J.W., Raudenbush, S.W. and Earls, F. (2003) Neighborhood support and the birth weight of urban infants. American Journal of Epidemiology, 157, 1-8. http://dx.doi.org/10.1093/aje/kwf170

[6] Messer, L.C., Kaufman, J.S., Dole, N., Savitz, D.A. and Laraia, B.A. (2006) Neighborhood crime, deprivation, and preterm birth. Annals of Epidemiology, 16, 455-462. http://dx.doi.org/10.1016/j.annepidem.2005.08.006

[7] Subramanian, S.V., Chen, J.T., Rehkopf, D.H., Waterman, P.D. and Krieger N. (2006) Comparing individual- and area-based socioeconomic measures for the surveillance of health disparities: A multilevel analysis of Massachusetts births, 1989-1991. American Journal of Epidemiology, 164, 823-834.

http://dx.doi.org/10.1093/aje/kwj313

[8] Collins, J.W. and David. R.J. (2009) Racial disparity in low birth weight and infant mortality. Clinics in Perinatology, 36, 63-73.

http://dx.doi.org/10.1016/j.clp.2008.09.004

[9] Blumenshine, P., Egerter, S., Barclay, C.J., Cubbin, C. and Braveman, P.A. (2010) Socioeconomic disparities in adverse birth outcomes. American Journal of Preventive Medicine, 39, 263-272. http://dx.doi.org/10.1016/j.amepre.2010.05.012

[10] Cubbin, C., Marchi, K., Lin, M., Bell, T., Marshall, H., Miller, C. and Braveman, P. (2008) Is neighborhood deprivation independently associated with maternal and infant health? Evidence from Florida and Washington. $M a-$ ternal and Child Health Journal, 12, 61-74. http://dx.doi.org/10.1007/s10995-007-0225-0

[11] Farley, T.A., Mason, K., Rice, J., Habel, J.D., Scribner, R. and Cohen, D.A. (2006) The relationship between the neighbourhood environment and adverse birth outcomes. Paediatric and Perinatal Epidemiology, 20, 188-200. http://dx.doi.org/10.1111/j.1365-3016.2006.00719.x

[12] Do, D.P. (2009) The dynamics of income and neighborhood context for population health: do long-term measures of socioeconomic status explain more of the black/ white health disparity than single-point-in-time measures? Social Science \& Medicine, 68, 1368-1375. http://dx.doi.org/10.1016/j.socscimed.2009.01.028

[13] Benzeval, M. and Judge, K. (2001) Income and health, the time dimension. Social Science \& Medicine, 52, 13711390. http://dx.doi.org/10.1016/S0277-9536(00)00244-6

[14] Reagan, P.B. and Salsberry, P.J. (2004) Race and ethnic differences in determinants of preterm birth in the USA: Broadening the social context. Social Science \& Medicine, 60, 2217-2228. http://dx.doi.org/10.1016/j.socscimed.2004.10.010

[15] Kaufman, J.S., Dole, N., Savitz, D.A. and Herring, A.H. (2003) Modeling community-level effects on preterm birth. Annals of Epidemiology, 13, 377-384. http://dx.doi.org/10.1016/S1047-2797(02)00480-5

[16] Pickett, K.E, Collins Jr., J.W., Masi, C.M. and Wilkinson, R.G. (2005) The effects of racial density and income incongruity on pregnancy outcomes. Social Science \& Medicine, 60, 2229-2238. http://dx.doi.org/10.1016/j.socscimed.2004.10.023

[17] Masi, C.M., Hawkley, L.C., Piotrowski, Z.H. and Pickett, K.E. (2007) Neighborhood economic disadvantage, violent crime, group density, and pregnancy outcomes in a diverse, urban population. Social Science \& Medicine, 65, 2440-2457.

http://dx.doi.org/10.1016/j.socscimed.2007.07.014

[18] Zielenbach, S. (2005) Understanding Community Change: A look as low-income Chicago neighborhoods in the 1990s. Urban Institute, No. 4.

[19] Kingsley, G.T. and Pettit, K.L.S. (2007) Concentrated poverty: Dynamics of change. Urban Institute, No. 5.

[20] Illinois Department of Public Health (2006) Vital Statistics Illinois. Illinois Center for Health Statistics, Springfield.

[21] World Health Organization (1993) International statistics classification of diseases and related health problems. 10th Edition, Vol. 2. WHO, Geneva.

[22] Bocksay, K.A., Harper-Jemison, D.M., Gibbs, K.P., Weaver, K. and Thomas, S.D. (2007) Community area health inventory part one: Demographic and health profiles. Health Status Index Series Vol. XVI No. CV, Chicago Department of Public Health Office of Epidemiology, Chicago.

[23] Hunter, A. and Janowitz, M. (1984) Symbolic communities: The persistence and change of Chicago's local communities. University of Chicago Press, Chicago.

[24] University of Michigan Population Studies Center (2002) Neighborhood Change Database (NCDB) Tract Data from 1970-2000.

http://www.psc.isr.umich.edu/dis/data/resource/detail/144 6

[25] Taylor, D.G. (2007) Income diversity and the context of community development. Metro Chicago Information Center, Chicago.

[26] Acevedo-Garcia, D., Soobader, M.J. and Berkman, L.F. (2007) Low birthweight among US Hispanic/Latino subgroups: The effect of maternal foreign-born status and education. Social Science \& Medicine, 65, 2503.

[27] Edwards, M.E. (2002) Education and occupations: Reexamining the conventional wisdom about later first births among American mothers. Sociological Forum, 17, 423-443.

[28] Centers for Disease Control and Prevention (2009) Assisted reproductive technology and trends in low birthweight-Massachusetts, 1997-2004. Morbidity and Mortality Weekly Report, 58, 49-52. 